\title{
Conceptual framework on teaching capacitors and inductors
}

\author{
Mustafa Erol ${ }^{a}$, Esra Bilal Önder ${ }^{b} *$ \\ Dokuz Eylül University, Cumhuriyet Blv, No:144, 35220, Alsancak, Konak, İzmir, Turkey \\ a mustafa.erol@deu.edu.tr, ${ }^{\mathrm{b}}$ esra.bilal@deu.edu.tr* \\ * Corresponding Author.
}

Received: 12 June 2021; Revised: 23 July 2021; Accepted: 30 July 2021

\begin{abstract}
The objective of this work is to suggest a conceptual framework on teaching capacitors and inductors in order to improve teaching abilities and to eliminate some fundamental misconceptions. The effort initially deals with resolution of physical structure and structural concepts/parameters of the devices and then resolves DC and AC responses of the inductors and capacitors. The resolutions are achieved by considering basic serious $\mathrm{RL}$ and $\mathrm{RC}$ circuits and resolving the circuits both theoretically and experimentally. As a result, an alternative teaching approach is offered and also a novel instructional material is developed and suggested. Some teaching clues are briefly inserted to guide teachers/instructors to reach a higher comprehension level. It is believed that the implications of the developed teaching material would be quite high and beneficial.

Keywords: Physics education, teaching capacitors, teaching inductors
\end{abstract}

How to Cite: Erol, M., \& Önder, E. B. (2021). Conceptual framework on teaching capacitors and inductors. Momentum: Physics Education Journal, 5(2), 182-193. https://doi.org/10.21067/mpej.v5i2.5630

\section{Introduction}

Capacitors and inductors likewise resistors are the most commonly used components in any electrical and electronics circuits and therefore stand at the center of fundamental teaching commitments in electricity and electronics (Young et al., 2011). Comprehension of the physics underneath DC and AC behaviors of the devices is vital to understand further processes concerning the structures and to eliminate certain misconceptions (Hasanah, 2020; Newburgh, 2002). In this sense, physical structures, description of the capacitance and inductance are among the most fundamental features and ought to be made clear for both physics and engineering students (Serway \& Jewett, 2018). Especially, distinct phase differences and also dissimilarities concerning DC and AC responses of the devices seem to be causing some major problems on understanding the mechanisms going on within the devices for majority of the students worldwide (Bilal Önder \& Önder, 2019; Coppens et al., 2017; Kezerashvili, 2012; Mitkowski et al., 2010). Nevertheless, understanding certain mechanisms and processes within the DC and AC circuits for both capacitors and inductors are in fact essential for educational purposes (Chekour, 2018; Jao, 2016).

Educational experiences conclude that capacitors are quite difficult to understand in the sense that it has an insulating layer nevertheless somehow conducts an electrical current (Ding et al., 2020; Stoyanov et al., 2019). Capacitors are also very interesting, for majority of the students, in the sense that concerning the DC circuits, it has a transient current and an accumulating voltage between the conducting plates. It has been seen that students have difficulty in understanding the factors affecting the capacitance of a capacitor and have a wrong view that capacitance depends on the potential difference on it and the charge on its plates (Demirci \& Çirkinoğlu, 2004; Li et al., 2012). AC response of the capacitors is also very interesting, for the students, due to demonstrating a clear phase shift relative to the resistor. There have been a number of studies focusing on clarifying certain teaching problems of the capacitors and their responses within the AC and DC circuits (Costa et al., 2007; 
Goodman, 2015; Trajkovic, 2011). In another study engineering students' knowledge of circuits with a resistor and a capacitor was examined and it was found that students had significant difficulties with unfamiliar circuit configurations (Pulé, 2012).

Similarly, inductors seem to be at the heart of certain educational difficulties. The physical structure of the inductors is only made up of an insulating coated conducting wire, nevertheless the origin of the voltage created across an inductor is commonly considered to be difficult to teach. Additionally, existence of a phase shift relative to the voltage of the resistor also arises certain teaching problems (Sterian et al., 2008). Therefore, teaching AC and DC responses of the inductors need to spend more attention and further considerations for a better understanding. There have been a number of studies illuminating certain teaching problems of the inductors and their responses within AC and DC circuits (Carstensen \& Bernhard, 2019). In a study conducted by (Salar et al., 2016), it was seen that the physics teacher candidates had insufficient knowledge about diodes, coils and capacitors and had difficulty in understanding the differences between alternating current and direct current.

\section{Method}

The present work focuses on suggesting an alternative approach and developing novel teaching materials that could easily be employed within the basic physics teaching classrooms and laboratories. The research approach can be classified as the descriptive approach and the research model can be named as developmental research model.

The work is based on answering the following problem statements that are specifically formulated to overcome certain teaching obstacles: (1) How can we teach structural concepts/parameters of capacitors and inductors in a better way to achieve higher comprehension levels?; (2) How can we conceptually teach differences on AC and DC responses of a capacitor (C) in a series RC circuit in a better way? And (3) How can we conceptually teach differences on AC and DC responses of an inductor $(\mathrm{L})$ in a series RL circuit in a better way?

\section{Structural Concepts of Capacitors}

\section{Results and Discussion}

Capacitors are mainly used to build up charge and consequently to store electrical energy within the electrical and electronics circuit (Young et al., 2011). Capacitors can be used in DC circuits for transient currents and permanent voltages and in AC circuits to vary alternating currents and voltages. Capacitors are comprised of two conducting plates and in-between an insulator is placed such that any current in the circuit accumulates charges on the conducting plates however cannot possibly travel through the insulator, as shown in Figure 1. Hence, by connecting capacitors to a circuit, depending on the exact case, capacitor plates are charged or discharged by the time.

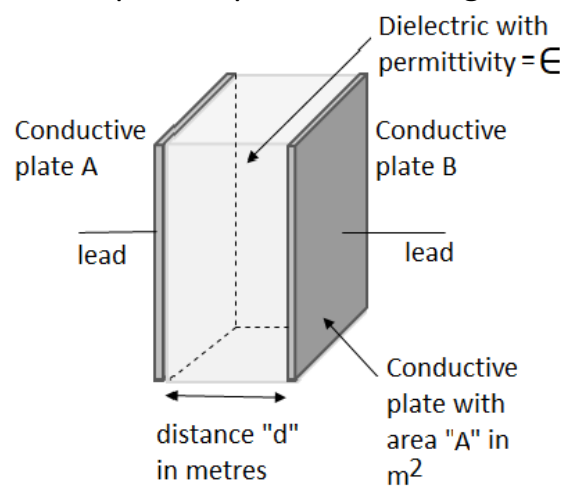

Figure 1. Structural Parameters of a Parallel Plate Capacitor

Figure 1 specifically shows the conducting plates of $A$ and $B$, distance between the plates, $d$, area of the plates, $A$, and insulating layer between the plates with a dielectric permittivity of $\in$. In the Figure $1,+Q$ and $-Q$ showing the amount of charges at an instant time of $t$. 
Teaching Clue: In capacitors, no current flows between the conducting plates inside the insulator.

The charge on a capacitor depends on the physical shape and properties of the plates and insulating layer. Physical properties, for parallel plate capacitors, are comprised of the overlapping area of the plates, $A$, thickness of the insulator, $d$, and dielectric permittivity of the insulator which is denoted by $\in$ for the material. Capacitance physically determines the maximum amount of charge that can possibly be accumulated on the plates. Capacitance of a parallel plate capacitor is structural, fixed and generally described by,

$C=\frac{€ A}{d}$

Teaching Clue: Capacitance of a capacitor depends only on physical parameters of the device and dielectric permittivity of the insulator, hence does not depend on voltage or charge accumulation speed.

Charging process of an empty capacitor starts by connection to a power supply and accumulating charge amount, at time of $t$, is simply given by,

$q(t)=C . V(t)$

where $V(t)$ denotes electrical voltage between the two conducting plates, $C$ denotes actual capacitance and $q(t)$ denotes amount of charge at any plate at an instant of $t$. The potential difference between the conducting plates, $V(t)$, changes due to the accumulation of the charges on the plates, $q(t)$, in the sense that as the instantaneous charge increases, that charges also oppose and slow down the further charge accumulation speed. Instantaneous current at any time is then given by, $i(t)=\frac{d q(t)}{d t}$, therefore time dependent instantaneous charge can be given by,

$q(t)=\int i(t) d t$

Instantaneous voltage difference between the capacitors' plates is then given by,

$V_{C}(t)=\frac{1}{c} \int i(t) d t$

Equation 4 is important to understand $D C$ and $A C$ responses of a capacitor. The equation states that a capacitor in fact integrates the instantaneous current in the circuit and the voltage difference between the two conducting plates is basically determined by the integrated current within the circuit.

Teaching Clue: Current at capacitor circuits continuously varies and voltage across the capacitor plates is determined by the integration of the current.

\section{Structural Concepts of Inductors}

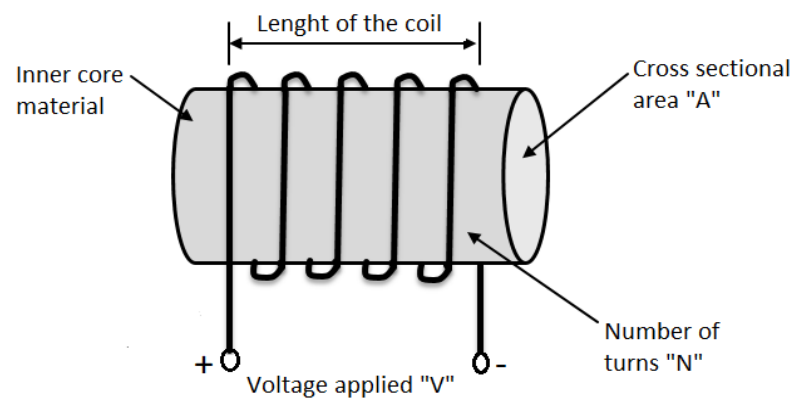

Figure 2. Structural Parameters of a Cylindrically Shaped Inductor

Inductors are simply made up of insulating coated conducting wire, winded around a cylinder, hence specially shaped to carry current loops. Inductors basically operate based on the fact that a 
current carrying wire creates magnetic fields around, in accordance with the Biot Savart's Law or alternatively Ampere's Law (Serway \& Jewett, 2018). Current loops obviously generate magnetic fields confined, by a large amount, inside the coil and uniform. Structural Parameters of a Cylindrically Shaped Inductor as shown in Figure 2.

Structural parameters of a cylindrically shaped inductor that are length of the coil, $l$, cross sectional area of $A$, number of turns or loops of $\mathrm{N}$ and magnetic permeability of the inner core material, $\mu$. The inner core material depending on the magnetic properties can increase the magnetic field strength by a factor of magnetic permeability.

Cylindrically shaped inductors are made up of certain physical parameters which are length of $l$, cross sectional area of $A$ and number of turns or loops of $N$ and magnetic permeability of the inner core material, $\mu$. When a current, $i(t)$, passes through the inductor/wire, electrical current simply generates an instantaneous magnetic induction of, $B(t)$. Magnetic induction inside the inductor, according to the Biot Savart 's Law or Ampere's Law, is given by,

$B(t)=\frac{\mu N i(t)}{l}$

where $N$ denotes the number of windings, $l$ denotes the length of the inductor and $\mu$ denotes the magnetic permittivity of the media within the inductor. Magnetic flux is defined as $\phi(t)=B(t) A$, and any change of magnetic flux within the inductor induces a clear voltage difference between the two ends of the inductor according to the well-known Faraday's Law (Young et al., 2011). Faraday's law states that the voltage is determined by the instantaneous magnetic flux change and given by,

$V_{L}(t)=\frac{d \phi(t)}{d t}$

where $\phi(t)$ denotes the magnetic flux.

Teaching Clue: Voltage across an inductor is only inducted by the change of the magnetic flux, nothing else.

Voltage across the inductor is then simply given by,

$V_{L}(t)=\frac{\mu N A}{l} \frac{d i(t)}{d t}$

where $L=\frac{\mu N A}{l}$ denotes the inductance of the inductor and depends on the physical properties of the inductor, such as length, $l$, number of windings, $N$, cross sectional area of $A$ and magnetic permittivity of the material within the inductor $\mu$.

Teaching Clue: Inductance of an inductor depends only on the physical parameters of the device and does not change with the current or voltage variations through the inductor.

Teaching Clue: Inductors simply differentiate instantaneous current and creates a net voltage differrence across the two ends.

Theoretical Resolution of DC and AC Behaviors of Capacitors

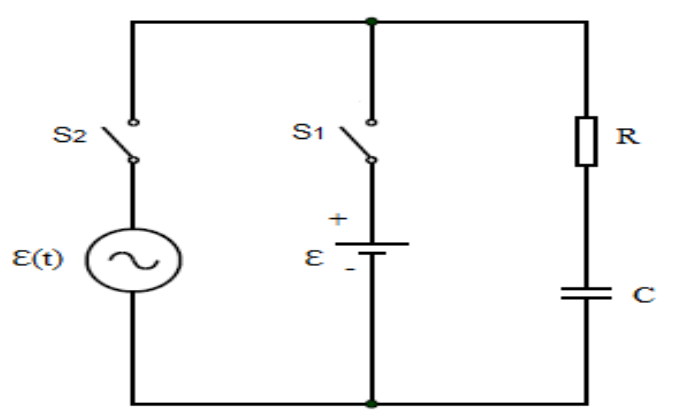

Figure 3. Circuit Employed to Resolve Both DC and AC Behaviors of Capacitors 
In order to theoretically resolve behaviors of a capacitor within DC and AC circuits, the basic circuit shown in Figure 3 is simply considered. The circuit consists of a capacitor of $C$, a resistor of $R$, an alternating and a direct voltage source and two switches.

In general, independently from type of the source, Kirchhoff's voltage law governs the instantaneous voltage which means that sum of the voltage changes within a current loop must be equal to zero, that is,

$\varepsilon(t)=i(t) R+\frac{q(t)}{c}$

In the case of only DC voltage source feeding the devices, that means $S_{1}$ is switched on and $S_{2}$ is off, the voltage feeding the circuit is constant, $\varepsilon(t)=\varepsilon$, then solution of the voltage equation leads to the instantaneous current decreasing exponentially in accordance with,

$i(t)=\frac{\varepsilon}{R} e^{-\frac{t}{R C}}$

Teaching clue: Capacitors, in DC circuits, can only carry transient currents, hence no permanent currents can be created.

In this equation, $\tau=R C$, denotes the time constant of the capacitor and practically determines the charging and discharging time scale of the capacitor. Specifically in the case of $t=3 \tau=3 R C$ the current decreases to approximately $\% 5$ of the maximum current which is $i_{m}=\frac{\varepsilon}{R}$. The expression also demonstrates that voltage on the resistor follows the exponential decrease of the current, that means, $V_{R}(t)=i(t) R$, and consequently instantaneous voltage across the capacitor increases accordingly,

$V_{c}(t)=\varepsilon\left(1-e^{-\frac{t}{R C}}\right)$

Teaching clue: Capacitors, in DC circuits, create permanent voltages which are equal to the voltage of the source.

If the voltage source is only $A C$ or sinusoidal, that means $S_{2}$ is closed and $S_{1}$ is open, then instantaneous voltage across the capacitor is given by the Equation (4) and capacitor in fact integrates the actual instantaneous current. Hence, assuming the current is given by $i(t)=i_{0} \sin$ (wt) then the instantaneous voltage is given by,

$V_{c}(t)=\left(\frac{i_{0}}{w c}\right) \sin \left(w t-\frac{\pi}{2}\right)$

This equation clearly demonstrates 90 degrees phase delay with respect to the voltage on the resistor $V_{R}(t)$ or with respect to the current on the circuit, $i(t)$. It is also obvious that the amplitude of the capacitors' voltage is given by $V_{M}=\frac{i_{0}}{w C}$, hence impedance of the capacitor can be expressed by $X_{C=} \frac{1}{w C}$.

Teaching clue: Capacitors, in AC circuits, create permanent sinusoidal voltages which demonstrate 90 degrees' phase shift, behind current or voltage of the resistor.

Theoretical Resolution of DC and AC Behaviors of Inductors

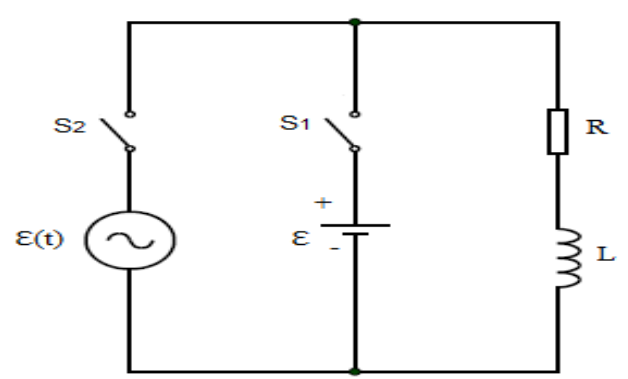

Figure 4. Circuit Employed to Resolve Both DC and AC Behaviors of Inductors 
In order to theoretically demonstrate performance of the inductors within DC and AC circuits, an elementary circuit shown in Figure 4 is considered. The circuit is principally composed of an inductor of $L$ with an electrical resistance of $R_{L}$, an external resistor of $R$, an alternating and a direct voltage source and two keys.

In this case, Kirchhoff's voltage law rules the instantaneous voltage that means sum of the voltage changes within a current loop must be equal to zero, which can be written by,

$\varepsilon(t)=i(t) R_{T}+L \frac{d i(t)}{d t}$

where overall resistance, $R_{T}$, includes the resistance of the inductor and external resistor, $R_{T}=R+R_{L}$. If only DC voltage source feeds the devices, that means $\mathrm{S}_{1}$ is switched on and $\mathrm{S}_{2}$ is off, then voltage feeding the circuit is constant, $\varepsilon(t)=\varepsilon$. Assuming that resistance $R_{T}$ includes the electrical resistance of the inductor $R_{L}$, solution of the Equation (12) leads to the instantaneous current in accordance with,

$i(t)=\frac{\varepsilon}{R_{T}}\left(1-e^{-\frac{t}{L / R_{T}}}\right)$

Teaching clue: Inductors, in DC circuits, create permanent currents which are simply equal to DC source voltage divided by overall resistance, $\frac{\varepsilon}{R_{T}}$.

The electrical resistance of the inductor is surely due to the various scattering processes that are determined by Ohm's law. Hence, it is obvious that electrical resistance of the inductor can be considered as negligible with respect to the actual external resistor so $R_{T} \cong R$ can be written, therefore $R_{L} \cong 0$ can easily be assumed. Time constant of the RL circuit can also be defined as $\tau=\frac{L}{R_{T}}$ which determines the time scale of the inductor for the DC circuits.

Consequently, instantaneous voltage across the inductor can be defined as,

$V_{L}(t)=\varepsilon e^{-\frac{t}{L / R_{T}}}$

Teaching clue: Inductors, in DC circuits, can only create transient voltages, hence no permanent voltages can be created.

If the voltage source is only $A C$ or sinusoidal, that means $S_{2}$ is closed and $S_{1}$ is open, then instantaneous voltage across the inductor, $V_{L}(t)$, is given by the Equation (7) and inductor simply differentiates the actual instantaneous current in accordance with,

$$
V_{L}(t)=L \frac{d i(t)}{d t}
$$

Hence, assuming the current is given by $i(t)=i_{0} \sin (w t)$ then instantaneous voltage is given by,

$$
V_{L}(t)=\left(i_{0} w L\right) \sin \left(w t+\frac{\pi}{2}\right)
$$

This equation clearly demonstrates 90 degrees' phase difference with respect to the voltage on the resistor $V_{R}(t)$ or with respect to the current on the circuit, $i(t)$. It is also apparent that the amplitude of the inductors' voltage is given by $V_{m}=i_{0} w L$, and the impedance of the inductor is expressed by $X_{L}=w L$.

Teaching clue: Inductors, in AC circuits, create permanent sinusoidal voltages which demonstrate 90 degrees' phase shift, in front of the current or the voltage of the resistor.

\section{Experimental results of DC and AC Responses of Capacitors}

In order to demonstrate $D C$ and $A C$ responses of the capacitors, for teaching purposes, the experimental setup in Figure 5 was designed by using a $1 \mu \mathrm{F}$ capacitor, $1 \mathrm{k} \Omega$ resistor and a signal generator. Time constant of the RC circuit is $\tau=1 \mathrm{~ms}$. 


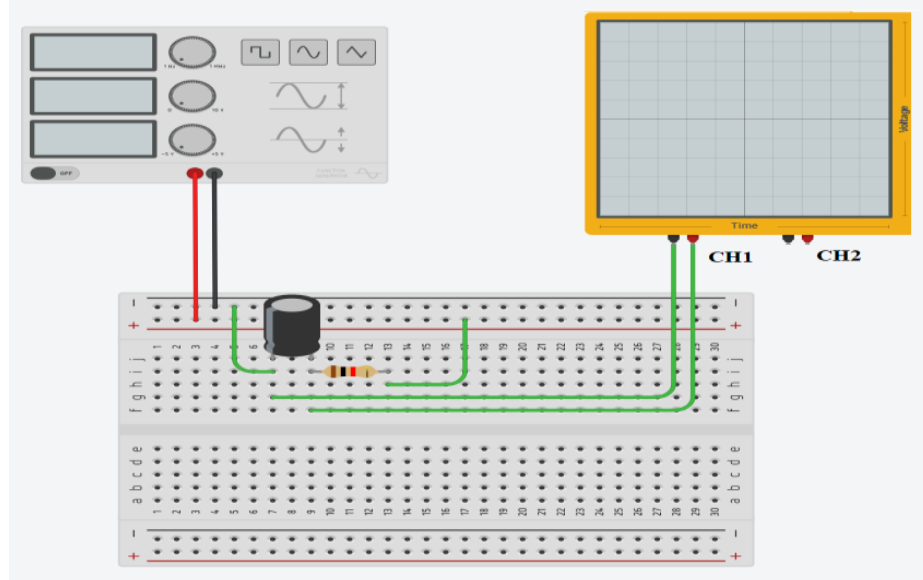

Figure 5. Experimental Setup Used for the RC Circuit

\section{Response of Capacitors}

In order to obtain DC response of the capacitor, a square wave with a long enough period $(T \geq 10 \tau)$ is applied to the circuit from the source signal generator. The smallest period, for a good observation on the oscilloscope, applied for this circuit is $\mathrm{T}=10 \mathrm{~ms}$ and corresponding frequency is $100 \mathrm{~Hz}$. Square voltage waves with a peak to peak value of $10 \mathrm{~V}$ and a frequency of $50 \mathrm{~Hz}$ were specifically used in our experiments. Voltage across the capacitor can theoretically be calculated by substituting instant time values of $t=1 \tau, 2 \tau, 3 \tau$ in the Equation (10). Corresponding measurements are achieved by using appropriate functions of the oscilloscope. Theoretically calculated and experimentally measured voltage values are given in Table 1 for certain consecutive instants.

Exponential voltage increases, in accordance with the Equation (10), were successively observed for approximately $t=1 \tau, 2 \tau$, and $3 \tau$ and relevant screenshots are shown in Figures $6 a, 6 b$ and $6 c$.

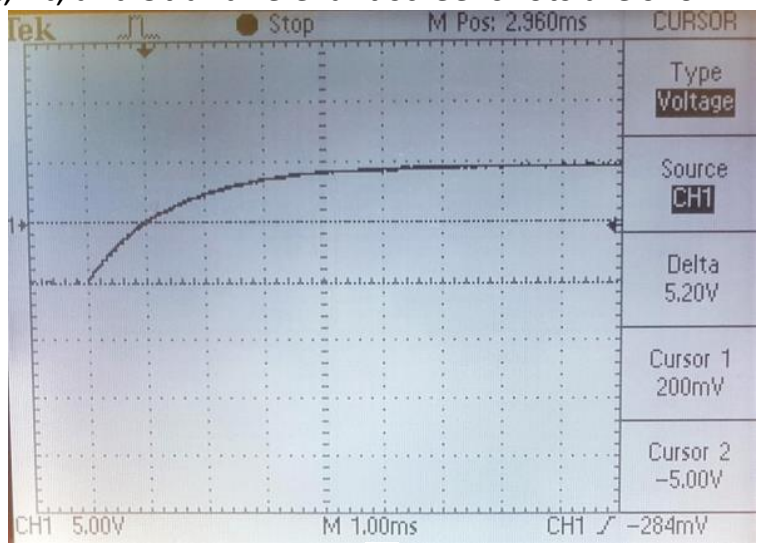

(a)

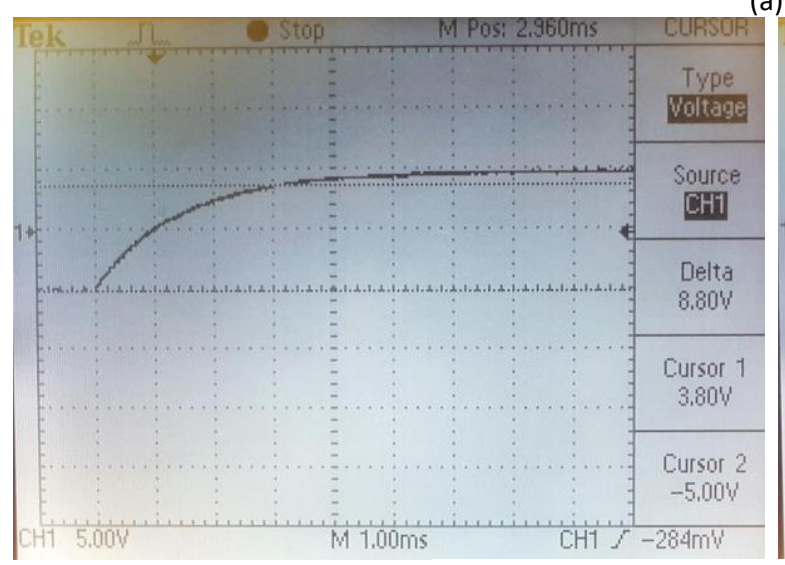

(b)

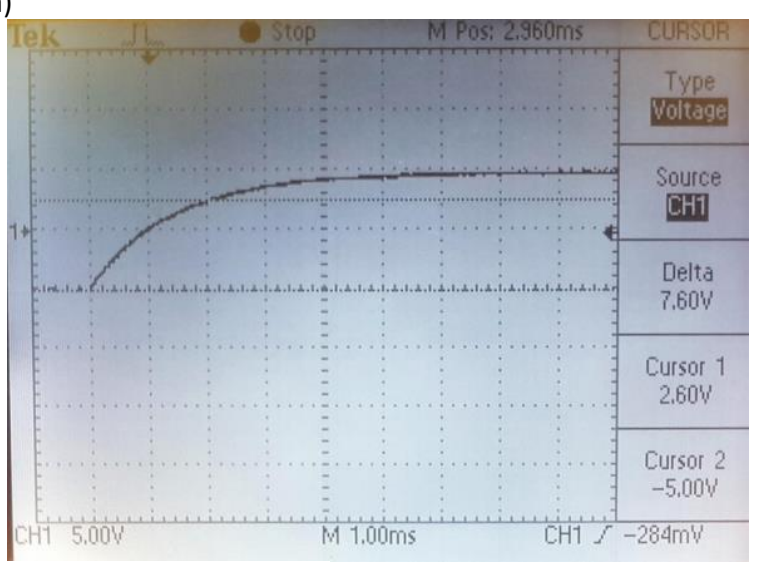

(c)

Figure 6. Experimental Voltage-Time Graphs of a Charging Capacitor at $(a) t=\tau,(b) t=2 \tau$, and (c) $t=3 \tau$ 
Momentum: Physics Education Journal, 5 (2), 2021, 189

Mustafa Erol, Esra Bilal Önder

Table 1. Theoretical and Experimental Voltage Values for Three Consecutive Values of Time

\begin{tabular}{ccc}
\hline \multirow{2}{*}{ Time } & \multicolumn{2}{c}{ Capacitor Voltage $(\mathrm{V})$} \\
\cline { 2 - 3 } & Theoretical & Experimental \\
\hline $1 \tau$ & 6.32 & 5.20 \\
$2 \tau$ & 8.64 & 7.60 \\
$3 \tau$ & 9.50 & 8.80 \\
\hline
\end{tabular}

Teaching Clue: Capacitors in DC circuits can only pass current for a short time depending on the time constant, however holds voltages permanently.

\section{AC Response of Capacitors}

In order to experimentally observe $A C$ response of the capacitors, a sinusoidal signal with a frequency of $1 \mathrm{kHz}$ and $15 \mathrm{~V}$ peak to peak amplitude is applied to the circuit in Figure 5 . To observe actual experimental change of the voltage of the resistor and capacitor, two ends of the capacitor were connected to channel 1 and input signal to channel 2 on the oscilloscope. Using the $\mathrm{CH} 2-\mathrm{CH} 1$ math function of the oscilloscope, solely voltage of the resistance was observed on the oscilloscope. In Figure 7, an oscilloscope image of the resistor with the larger amplitude and the capacitor image with the smaller amplitude are given.

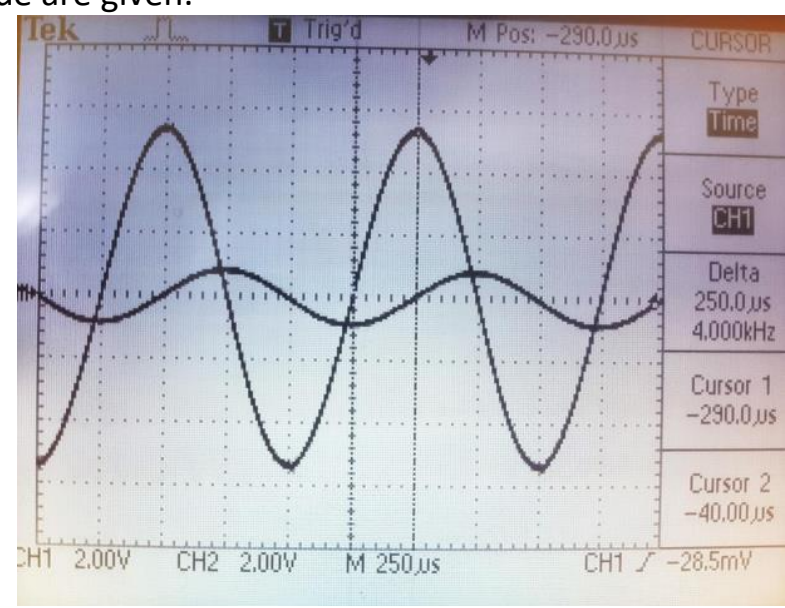

Figure 7. AC voltage-time graphs obtained experimentally are shown for the both resistor (larger amplitude) and capacitor (smaller amplitude)

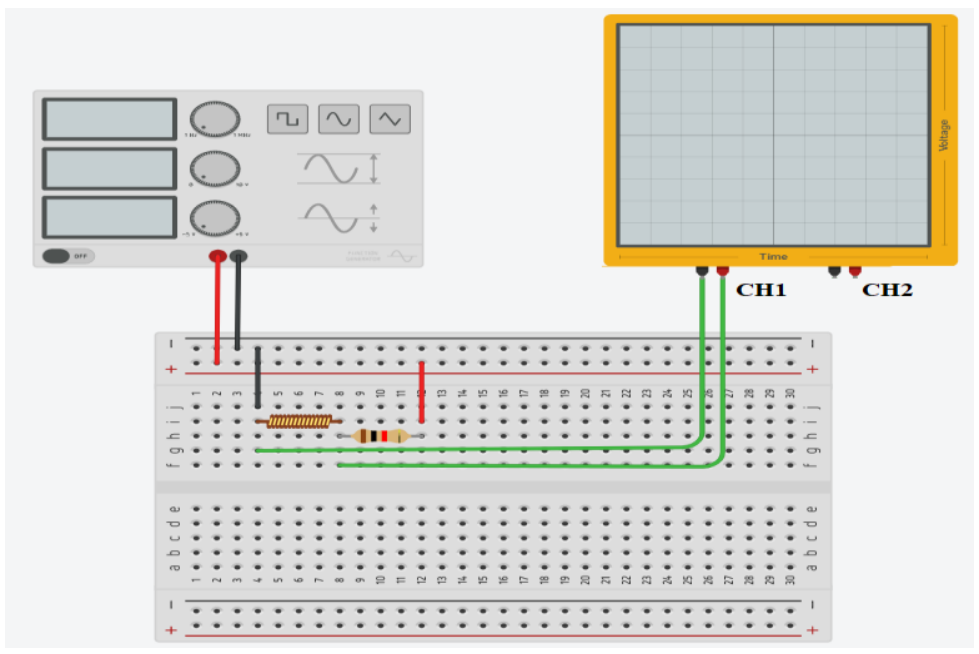

Figure 8. Experimental Setup for RL Circuit

In order to specifically observe voltage waveforms across the resistor and capacitor, an input signal with the frequency of $1 \mathrm{kHz}$ and a period of $1 \mathrm{~ms}$ were used for the measurements. It is clearly seen, from the Figure 7, that the difference between the cursors is about $250 \mu \mathrm{s}$. This shows that 
there is a $90^{\circ}$ phase difference between the voltage of the capacitor and the voltage of the resistor and therefore the current in the circuit.

Teaching Clue: Capacitors create voltage signals with a 90-degree phase shift behind the current signal or the voltage signal across the resistor due to the charging process.

\section{Experimental results of DC and AC Responses of Inductors}

In order to observe $D C$ and $A C$ responses of the inductors, an experimental setup given in Figure 8 was created using a $1 \mathrm{mH}$ inductor, $1 \mathrm{k} \Omega$ resistor and a signal generator. Hence, the time constant of the inductor in the circuit is set to be $\tau=1 \mu \mathrm{s}$.

\section{Response of Inductors}

In order to detect DC response of the inductors, a square waveform with a long enough period $(T \geq 10 \tau)$ is applied to the circuit from the source signal generator. The smallest period applied for a clear observation on the oscilloscope is $T=10 \mu \mathrm{s}$ and corresponding frequency is $100 \mathrm{kHz}$. Square voltage waves with a peak to peak value of $10 \mathrm{~V}$ and a frequency of $1 \mathrm{kHz}$ were specifically used in our experiments. The voltage across the inductor can obviously be estimated by substituting instant time values of $t=1 \tau, 2 \tau, 3 \tau$ in the Equation (14). Corresponding measurements are experimentally achieved on the oscilloscope by using appropriate functions of the scope. Theoretically calculated and experimentally measured voltage values are given in Table 2 .

Table 2. Theoretical and Experimental Voltage Values for Three Consecutive Values of Time

\begin{tabular}{ccc}
\hline \multirow{2}{*}{ Time } & \multicolumn{3}{c}{ Inductor Voltage $(\mathrm{V})$} \\
\cline { 2 - 3 } & Theoretical & Experimental \\
\hline $1 \tau$ & 3.67 & 3.80 \\
$3 \tau$ & 1.35 & 1.0 \\
& 0.49 & 0.40 \\
\hline
\end{tabular}

Exponentially decreasing voltage values across the inductor was observed on the oscilloscope for approximately $t=1 \tau, 2 \tau$, and $3 \tau$ and all are shown in Figure 9 .

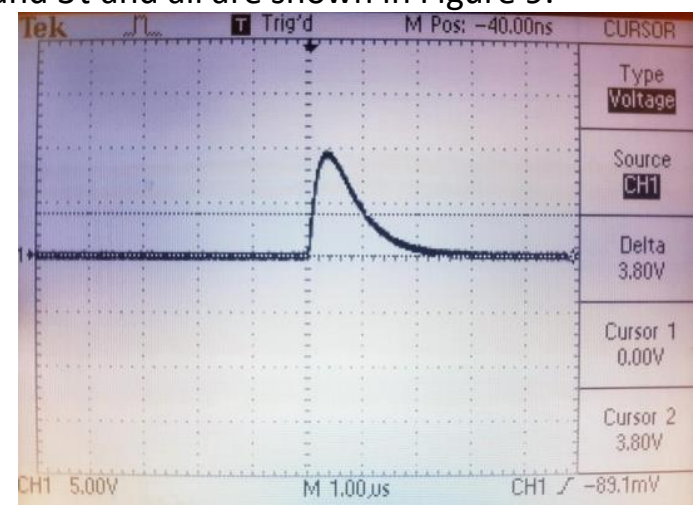

(a)

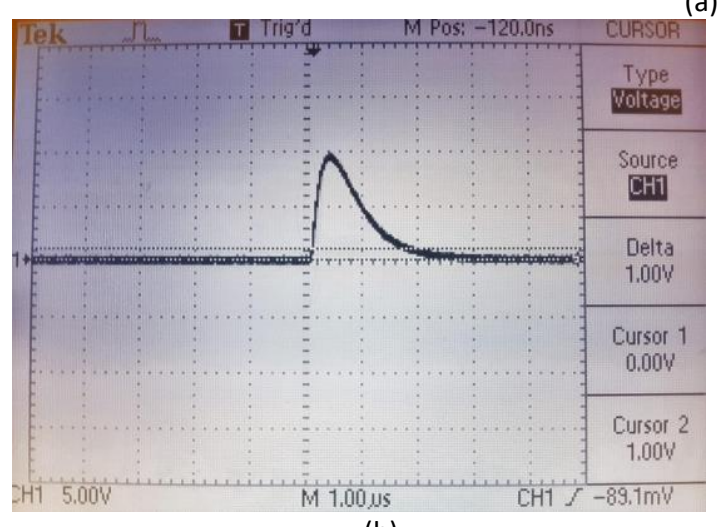

(b)

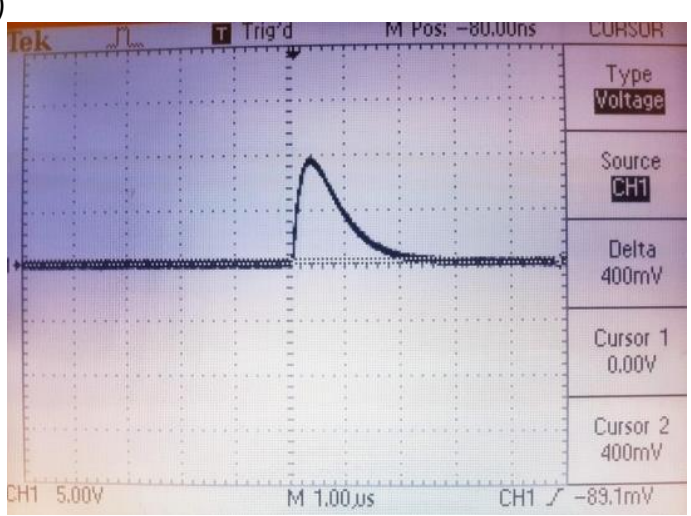

(c)

Figure 9. Voltage-Time Graph of an Inductor at $(a) t=1 \tau,(b) t=2 \tau$ and $(c) t=3 \tau$ 
Teaching Clue: Inductors in DC circuits can pass permanent current however holds the voltage for a very short time.

\section{AC Response of Inductors}

In order to see $A C$ response of the inductors, a sinusoidal waveform with a frequency of $100 \mathrm{kHz}$ and $15 \mathrm{~V}$ peak to peak amplitude is applied to the circuit in Figure 8 . In order to see change of the voltage across the resistor and inductor, two ends of the inductor were connected to channel 1 and input signal to channel 2 on the oscilloscope. Using the $\mathrm{CH} 2-\mathrm{CH} 1$ math function of the oscilloscope, voltage of the resistance is observed on the oscilloscope. In Figure 10, an oscilloscope image of the resistor with the larger amplitude and image of the inductor with the smaller amplitude are presented.

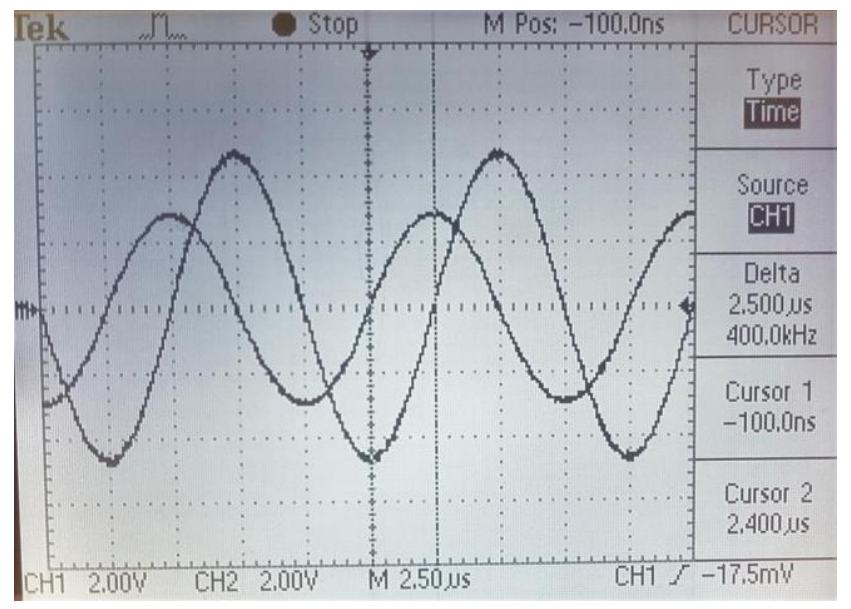

Figure 10. AC Voltage-Time Graphs Obtained Experimentally Are Shown for the Inductor (Larger Amplitude) and Resistor (Smaller Amplitude)

In order to specifically observe voltage waveforms across the resistor and inductor, a signal with frequency of $1 \mathrm{kHz}$ and period of $1 \mathrm{~ms}$ is used in the circuit. When Figure 8 is examined, it is clearly seen that the difference between the cursors corresponding waveforms is $250 \mu \mathrm{s}$. This underlines that there is a $90^{\circ}$ phase difference between the voltage of the inductor and the voltage of the resistor and therefore the current in the circuit.

Teaching Clue: Inductors create a voltage waveform with a 90-degree phase shift in front of the current or the voltage across the resistor due to the magnetic flux or current change.

\section{Conclusions}

This work is an effort to eliminate some common misconceptions and learning difficulties on capacitors and inductors. The effort initially deals with resolution of physical structures and structural concepts/parameters of the devices by defining the capacitance and inductance, underlining that the structural concepts are independent of the external factor, namely applied voltages or current changes. Resolutions of the devices are achieved by considering basic serious RL and RC circuits and by resolving the circuits theoretically and also experimentally. Teaching framework, which offers a number of teaching clues, is considered to be helpful in order to improve instructional abilities and to suggest a better comprehension of the inductors and capacitors. The effort is also thought to be important to eliminate some important misconceptions and misinterpretations widely observed in electricity and electronics.

\section{References}

Bilal Önder, E., \& Önder, F. (2019). Students' understanding of fundamental AC signal concepts. Canadian Journal of Physics, 97(11), 1225-1228. https://doi.org/10.1139/cjp-2018-0819

Carstensen, A.-K., \& Bernhard, J. (2019). Design science research - a powerful tool for improving 
methods in engineering education research. European Journal of Engineering Education, 44(12), 85-102. https://doi.org/10.1080/03043797.2018.1498459

Chekour, M. (2018). The impact perception of the resonance phenomenon simulation on the learning of physics concepts. Physics Education, 53(5), 055004. https://doi.org/10.1088/13616552/aac984

Coppens, P., Van den Bossche, J., \& De Cock, M. (2017). Student understanding of first order RC filters. American Journal of Physics, 85(12), 937-947. https://doi.org/10.1119/1.5003805

Costa, L. R. J., Honkala, M., \& Lehtovuori, A. (2007). Applying the problem-based learning approach to teach elementary circuit analysis. IEEE Transactions on Education, 50(1), 41-48. https://doi.org/10.1109/TE.2006.886455

Demirci, N., \& Çirkinoğlu, A. (2004). Öğrencilerin elektrik ve manyetizma konularında sahip oldukları ön bilgi ve kavram yanılgılarının belirlenmesi. Journal of Turkish Science Education, 1(2), 116138. http://www.tused.org/index.php/tused/article/view/46

Ding, L., Jia, Z., \& Zhang, P. (2020). From learning capacitance to making capacitors: The missing critical sensemaking. International Journal of Science and Mathematics Education, 1-17. https://doi.org/10.1007/s10763-020-10112-7

Goodman, L. (2015). Effects of a dialogical argumentation instructional model on science teachers' understanding of capacitors in selected Western Cape schools [University of the Western Cape]. https://etd.uwc.ac.za/handle/11394/5062

Hasanah, U. (2020). The effectiveness of STEM education for overcoming students' misconceptions in high school physics: Engineering viewpoint. Science Education International, 31(1), 5-13. https://doi.org/10.33828/sei.v31.i1.1

Jao, J.-C. (2016). Effectiveness of team-based learning on academic performance in an electric circuit theory course for health sciences students. World Transactions on Engineering and Technology Education, 14(2), 277-281. http://www.wiete.com.au/journals/WTE\&TE/Pages/Vol.14, No.2 (2016)/07-Jao-JC.pdf

Kezerashvili, R. Y. (2012). Teaching RC and RL Circuits using computer-supported experiments. IERI Procedia, 2, 609-615. https://doi.org/10.1016/j.ieri.2012.06.142

Li, J., Singh, C., Rebello, N. S., Engelhardt, P. V., \& Singh, C. (2012). Students' difficulties with equations involving circuit elements. 243-246. https://doi.org/10.1063/1.3680040

Mitkowski, S. A., Dąbrowski, A. M., Porębska, A., \& Kurgan, E. (2010). Electrical engineering education in the field of electric circuits theory at AGH University of Science and Technology in Kraków. Proc. 1st World Conf. on Technol. and Engng. Educ, 47-53. http://www.wiete.com.au/conferences/2wctee/papers/8-10-Mitkowski.pdf

Newburgh, R. (2002). Conceptual difficulties with rates of change, or Zeno redux. Physics Education, 37(2), 147-151. https://doi.org/10.1088/0031-9120/37/2/308

Pulé, S. (2012). Students' versatility with resistor-capacitor circuits. International Journal of Electrical Engineering and Education, 49(4), 419-443. https://doi.org/10.7227/IJEEE.49.4.5

Salar, R., Emine, U., Karaman, I., \& Turgut, Ü. (2016). Fizik öğretmeni adaylarının 12. sınıf elektrik ve elektronik konusunu ile ilgili bilgi düzeyleri. Trakya Üniversitesi Eğitim Fakültesi Dergisi, 6(1), 41-54. https://dergipark.org.tr/en/pub/trkefd/issue/21483/230223

Serway, R. A., \& Jewett, J. W. (2018). Physics for scientists and engineers (3rd ed.). Cengage Learning.

Sterian, A., Adamczyk, B., \& Rahman, M. M. A. (2008). A project-based approach to teaching introductory Circuit Analysis. 2008 38th Annual Frontiers in Education Conference, S1F-3-S1F-8. https://doi.org/10.1109/FIE.2008.4720491

Stoyanov, I., Evstatiev, B., Iliev, T., \& Mihaylov, G. (2019). Adaptive learning for virtual investigation of capacitors' electrical and physical properties. 2019 IEEE 25th International Symposium for Design and Technology in Electronic Packaging (SIITME), 58-61. 
Momentum: Physics Education Journal, 5 (2), 2021, 193

Mustafa Erol, Esra Bilal Önder

https://doi.org/10.1109/SIITME47687.2019.8990834

Trajkovic, L. (2011). Teaching circuits to new generations of engineers. 2011 IEEE International Symposium of Circuits and Systems (ISCAS), 1187-1190. https://doi.org/10.1109/ISCAS.2011.5937781

Young, H. D., Freedman, R. A., \& Ford, A. L. (2011). Sears and Zemansky's University Physics: With modern physic (13th ed.). Addison-Wesley. 